\title{
Increased mortality in HER2 positive, oestrogen receptor positive invasive breast cancer: a population-based study
}

\author{
CA Purdie*,', L Baker², A Ashfield², S Chatterjee ${ }^{3}$, LB Jordan', P Quinlan², DJA Adamson ${ }^{3}$, JA Dewar ${ }^{3}$ and \\ AM Thompson ${ }^{2}$
}

'Department of Pathology, Ninewells Hospital and Medical School, Dundee DDI 9SY, UK; '2 Department of Surgery and Molecular Oncology, Ninewells Hospital and Medical School, University of Dundee, Dundee DDI 9SY, UK; ${ }^{3}$ Department of Clinical Oncology, Ninewells Hospital and Medical School, Dundee DDI 9SY, UK

\begin{abstract}
BACKGROUND: This study assessed the impact of human epidermal growth factor receptor 2 (HER2) status on the outcomes in an unselected population of breast cancer patients who did not receive HER2-targeted therapy.

METHODS: HER2 status by immunohistochemistry and fluorescence in situ hybridisation was compared with clinicopathological data, overall survival (OS) and disease-free survival (DFS) for all patients presenting with breast cancer over 3 years.

RESULTS: In 865 patients (median follow up 6.02 years), HER2 positivity was identified in 13.3\% of all cancers and was associated with higher tumour grade $\left(P<10^{-8}\right)$, lymphovascular invasion $(P<0.001)$ and axillary nodal metastasis $(P=0.003)$. There was a negative association with oestrogen-receptor (ER) and progesterone-receptor expression $\left(P<10^{-8}\right)$, but the majority $(57 \%)$ of HER2 + tumours were ER + HER2 positivity was associated with poorer OS $(P=0.0046)$ and DFS $(P=0.000 \mathrm{I})$ confined to the lymph node-positive $(\mathrm{LN}+)$ and $\mathrm{ER}+$ subgroups.

CONCLUSION: HER2-positive cancers were less common in this population-based cohort than most selected series. The association of HER2 positivity with poor prognosis was confined to the ER + and LN + subgroups. The survival deficit for the $7.5 \%$ of patients with $\mathrm{ER}+/ \mathrm{HER} 2+$ cancer compared with ER + /HER2 - patients points to a significant subgroup of women who may not (currently) be considered for HER2-directed therapy.

British Journal of Cancer (2010) 103,475-48I. doi:I0.1038/sj.bjc.6605799 www.bjcancer.com
\end{abstract}

Published online 27 July 2010

(c) 2010 Cancer Research UK

Keywords: breast cancer; oestrogen receptor; HER2; survival; population

The human epidermal growth factor receptor 2 (HER2) gene is the human homologue of the rat oncogene neu, originally identified as a result of transformation of mouse fibroblasts by DNA derived from a chemically induced rat neuroblastoma (Shih et al, 1981). This gene was shown to be homologous to the avian erythroblastosis virus $(v$-erb $B)$ and the cellular epidermal growth factor receptor (EGFR) (Schechter et al, 1984, 1985). An EGFR-related gene was subsequently shown to be amplified in a human breast cancer cell line and named HER2 (King et al, 1985). HER2 is a member of a type 1 trans-membrane protein family characterised by an extracellular ligand-binding domain, a trans-membrane domain and an intracellular tyrosine kinase domain. Ligand binding results in a conformational change causing tyrosine kinase activation and intracellular signalling. HER2 has no known ligand and probably operates by way of heterodimerisation with HER3 (Moasser, 2007). HER2 over-expression has been shown to result in increased invasiveness and tumourigenicity as well as increased proliferation, tumourigenic growth and transformed characteristics (Moasser, 2007).

*Correspondence: Dr CA Purdie; E-mail:colin.purdie@nhs.net Received 3I March 2010; revised 18 June 2010; accepted I 8 June 20 I0; published online 27 July 2010
The significance of HER2 in human breast cancer was first identified when gene amplification was described in 30\% of invasive tumours (Slamon et al, 1987) and further studies showed that this amplification is commonly associated with elevated HER2 mRNA and protein levels (Slamon et al, 1989) with the oncogenic effects of HER2 in human cancer being the result of gene amplification rather than mutation (Slamon et al, 1987). In early studies, HER2 gene amplification was shown to predict poor prognosis (overall survival (OS) and disease-free survival (DFS)) and, furthermore, HER2 amplification was an independent prognostic variable superior to all other known variables except nodal metastasis (Slamon et al, 1987, 1989). The prognostic influence of HER2 positivity was shown in the node-positive (but not in node-negative) patient group (Slamon et al, 1987, 1989).

Subsequent studies have presented conflicting data regarding the significance of HER2 positivity in relation to nodal metastasis. Some suggest that HER2 amplification (Seshadri et al, 1993; Chia et al, 2008), over-expression (Press et al, 1993; Menard et al, 2008) or a combination of both (Chia et al, 2008; Curigliano et al, 2009; Gonzalez-Angulo et al, 2009; Tovey et al, 2009) do predict outcome in node-negative patients, whereas a large pooled analysis of similar studies (selected on the basis of sufficient population size and follow-up) suggest that they do not (Mirza et al, 2002). Some 
reasons for the conflicting evidence include patient selection, short follow-up, markedly differing methodologies for the assessment of HER2 amplification and over-expression (Ravdin and Chamness, 1995 ) and that in some studies 'prognosis' refers to DFS or relapsefree survival and not overall or breast cancer-specific survival (Curigliano et al, 2009; Gonzalez-Angulo et al, 2009).

HER2-targeted therapy showed clinical utility through trials with trastuzumab, which showed increased time to progression in advanced disease (Slamon et al, 2001), increased frequency of complete pathological response in the neo-adjuvant setting (Buzdar et al, 2005) and prolonged DFS and OS in the adjuvant setting (Piccart-Gebhart et al, 2005; Romond et al, 2005; Smith et al, 2007; Perez and Baweja, 2008). Subsequently, further clinically useful therapies such as lapatinib have emerged (Perez and Baweja, 2008). Whereas trastuzumab may also be active in some HER2 - disease; the underlying mechanism for this is unclear (Paik et al, 2008) and the focus remains on discerning which patients with HER2 + cancers might benefit from and should receive HER2-directed therapy.

The published frequency of HER2 amplification ranges between 8 and 30\% (Seshadri et al, 1993; Press et al, 1997; Ellis et al, 2005; Crowe et al, 2006; Park et al, 2006; Frogne et al, 2009; Sauter et al, 2009; Tovey et al, 2009) and protein over-expression even more widely, between 2 and 50\% (Slamon et al, 1989; Koeppen et al, 2001; Sauter et al, 2009) although, again, these studies differ in the methodologies used and the populations studied. The true frequency of HER2 amplification may be of the order of $15-17 \%$ in a less selected population (Walker et al, 2008) and a recent review of HER2 testing suggests fluorescence in situ hybridisation (FISH) rather than immunohistochemistry (IHC) testing could be considered as the primary clinical test (Sauter et al, 2009). However, such a reliance on FISH testing alone can risk missing patients who overexpress HER2 but are not amplified on FISH.

Here we report the first population-based study, which has examined an unselected, consecutive series of invasive breast cancers presenting to a single cancer centre over a 3-year period. The aim of the study was to identify the true prevalence of HER $2+$ breast cancer and to explore the therapeutic and clinical implications in a population who had not received HER2-targeted therapy.

\section{MATERIALS AND METHODS}

\section{Study population}

The patients in this study comprise an unselected, consecutive series of 920 patients with invasive breast cancer presenting to the Regional Cancer Centre between 1 June 2000 and 30 June 2003. This represents 3 full years and the start of the study corresponds with the point at which HER2 analysis of all breast cancers became routine practice in Tayside, Scotland.

The Cancer Centre treats all screen detected and symptomatic breast cancer patients from a defined geographic area (Tayside) with all patient records (including pathology and follow-up) maintained within one institution ensuring a complete database. The population within this region is relatively homogenous, Caucasian and stable in terms of movement into and out of the region, ensuring good follow-up and high levels of data completeness. The clinical data recorded included age at diagnosis, sex, mode of referral, final surgical treatment and adjuvant therapy. All patients undergoing curative surgery had adjuvant therapy (including chemotherapy) as per the Scottish Intercollegiate Guidelines Network (SIGN) guidelines (SIGN, 2005). Data on adjuvant chemotherapy and endocrine therapy were obtained from the oncology database. No patients received therapy directed at HER2 or other members of the EGFR family as this study documents outcomes before the licence of any HER2-directed therapy in this setting.

\section{Pathology}

All patients had pathology review by a single specialist breast pathologist (CAP) working within a pathology laboratory, which is fully accredited by Clinical Pathology Accreditation UK (CPA UK) Ltd. Data were recorded as per the National Health Service Breast Screening Programme Guidelines (NHSBSP) (1995) concerning tumour grade, tumour size, lymph node (LN) status and presence of lymphovascular invasion. The Nottingham Prognostic Index (NPI) was derived from these data (Haybittle et al, 1982; Galea et al, 1992).

\section{Oestrogen receptor and progesterone receptor}

Immunohistochemistry was carried out on diagnostic core biopsies using primary antibodies for oestrogen receptor (ER) (clone 6F11, 1:200) and progesterone receptor (PR) (clone 16, $1: 800$ ); both from Novocastra Laboratories Ltd, Newcastle Upon Tyne, UK. Antigen retrieval for ER and PR was carried out using a microwave pressure vessel followed by processing on a DAKO TechMate 500 Plus autostainer (Dako, Denmark) with the Dako REAL detection system (an indirect streptavidin/biotin method using anti-mouse antibody) and visualised with horseradish peroxidase and diaminobenzadine. The stained slides were scored using the 'quickscore' method (Detre et al, 1995). Cases scoring $0-3$ were regarded as negative from the point of view of endocrine therapy, whereas cases scoring $\geqslant 4$ were regarded as positive.

\section{HER2 assessment}

HER2 assessment (IHC and in situ hybridisation) was carried out in laboratories accredited by CPA UK Ltd and quality assured by the UK National External Quality Assurance Scheme.

All cases underwent HER2 IHC using the CB11 monoclonal antibody on the diagnostic core biopsy as previously described (Purdie et al, 2010) and scored using published criteria (Ellis et al, 2000; Walker et al, 2008). All of those cancers scoring 'equivocal $(2+)$ ' were subjected to HER2 FISH analysis. HER2 FISH was carried out using the PathVysion HER2 DNA probe kit (Vysis, Abbott Laboratories, Abbott Park, IL, USA) and assessed as described using standard criteria (Purdie et al, 2010). Briefly, the ratio of orange HER2 signals to green alpha satellite CEP17 signals was calculated and amplification defined as a ratio of $\geqslant 2.00$. Cases scoring IHC negative $(0)$, IHC negative $(1+)$ or IHC equivocal $(2+)$ but FISH negative were classified as HER2 negative and those scoring IHC equivocal $(2+)$ and FISH positive or IHC positive $(3+)$ were regarded as HER2 positive.

\section{Follow-up}

Follow-up data were obtained from the Cancer Centre breast oncology database. Where necessary, these data were backed up by contact with the patient's general medical practitioner or the registrar of deaths. Because of the stable nature of this population, complete follow-up data were obtained for all 776 patients who underwent surgery. In the case of patients who died, the date and the cause of death was recorded. All deaths that were not attributable to breast cancer were censored at the date of death. For those patients who developed recurrence during follow-up, the date of first recurrence was recorded along with the site of relapse; this being designated as local, regional or distant. Accordingly, the primary end points were breast cancer-specific OS and breast cancer-specific DFS.

\section{Statistical analysis}

All associations for $2 \times 2$ tables were carried out using a two-sided Fisher's Exact Test. For $3 \times 2$ tables a chi-squared $\left(\chi^{2}\right)$ test with 
Yates' correction was used. As the immunohistochemical analyses (ER, PR, HER2) were carried out on the diagnostic core biopsies, it was possible to test for associations between these parameters for all tumours undergoing biopsy. The pathological data on tumour grade, size, lymphovascular invasion, LN status and NPI can only be obtained from the surgical resection specimens, in which the entire tumour and LNs can be examined. These data are therefore confined to patients undergoing surgery. The planned subgroup analyses included these conventional pathological and hormone receptor expression parameters.

Survival analysis was carried out by Kaplan-Meier survival curves analyzed by the log-rank test. Multivariate analysis was carried out using Cox's regression.

\section{Multiple tumours}

In the 39 patients who had multiple tumours and underwent surgery, the cancer with the highest NPI was used as the index lesion for the survival analysis as this tumour was the biologically most aggressive. In every case the tumour producing the highest NPI was also the tumour with the highest pathological grade. Furthermore, in all of the patients who had multiple tumours, one of which was HER2 +, the HER2 + tumour was also the highest-grade tumour and the tumour with the highest NPI.

\section{RESULTS}

\section{Study population}

A total of 920 female patients, mean age 61.7 years (range 25.8-96.9), diagnosed with invasive breast cancer between 1 June 2000 and 30 June 2003 had 965 tumours (41 of the patients had two or more cancers) (Figure 1). Fifty five patients $(6.0 \%)$ only had a cytological diagnosis of malignancy on fine needle aspirate and no histological (biopsy) diagnosis, as co-morbidity or advanced disease at presentation precluded surgery. The remaining 865 (94.0\%) patients underwent core biopsy of the primary breast tumour for ER, PR and HER2 analysis. In all, 89 of the 865 patients only had a core biopsy and no surgery because of co-morbidities or advanced disease at presentation. Overall 776 of the 865 patients underwent surgical resection with median duration of follow-up 6.02 years (range 63-100 months) and the pathological dataset included tumour size, tumour grade, presence of lymphovascular invasion (LVI), LN status and NPI.

All of the patients in this study who had ER + tumours were prescribed endocrine therapy. At the time of this study this was tamoxifen. Chemotherapy (predominantly anthracycline based) was administered to $26.2 \%$ of the patients in this study with a significantly higher proportion in HER $2+$ patients than in the HER 2 - patients (45.7 vs $23.2 \%$ respectively, $P<0.0001)$. In the node-negative group, this trend continued with $26.4 \%$ of HER2 + and $9.3 \%$ of HER 2 - patients being given chemotherapy $(P<0.001)$.

\section{Pathology}

The distribution of pathological parameters (Supplementary Table 1) showed the proportions that would be expected for a population which, in 2000-2003, was predominantly symptomatic (82\%) in the presentation (Elston, 1984; Elston and Ellis, 1991; Galea et al, 1992). The Kaplan-Meier plots for survival confirmed that, as expected, tumour grade $(P<0.001)$, LN status $(P<0.001)$, NPI $(P<0.001)$, ER status $(P<0.001)$ and $P R$ status $(P<0.001)$ were all predictive of OS and DFS (data not shown). Of the 910 cancers biopsied, $81.1 \%$ were ER + and $69.6 \% \mathrm{PR}+$.

\section{HER2 status}

The median age at diagnosis was not significantly different for patients with HER2 + (59.4 years) vs HER2 - (61.8 years) cancers



Figure I CONSORT diagram of patient and tumour groups. ${ }^{\text {a } 35}$ patients had 2 tumours, 4 patients had 3 tumours. ${ }^{\text {b }}$ Two patients in this group had two tumours, each. HER2, human epidermal growth factor receptor 2; LN, lymph node.

Table I HER2 characteristics of all cancers in biopsy series

\begin{tabular}{lrrrr}
\hline HER2 characteristics (IHC) & N & $\%$ & N & $\%$ \\
\hline Negative (0) & 254 & 27.9 & & \\
Negative (I+) & 455 & 50.1 & 788 & 86.7 \\
Equivocal (2+) FISH- & 79 & 8.7 & & \\
Equivocal (2+) FISH+ & 50 & 5.5 & 121 & 13.3 \\
Positive (3+) & 71 & 7.8 & & \\
Total & $909^{\mathrm{a}}$ & 100.0 & $909^{\mathrm{a}}$ & 100.0 \\
\hline
\end{tabular}

Abbreviations: $\mathrm{FISH}=$ fluorescent in situ hybridization; $\mathrm{HER} 2=$ human epidermal growth factor receptor 2; $\mathrm{HHC}=$ immunohistochemistry. HER2 characteristics of the 910 breast cancers in the biopsy series. ${ }^{2} \mathrm{No}$ HER2 status was available for one cancer (IHC 'equivocal $2+$ ' but insufficient tissue for FISH analysis).

( $P=0.29$, Mann - Whitney $U$-test $)$ with no significant difference in the frequency of HER2 positivity by age decile $(20-90)$. The results of the HER2 analysis (Table 1) showed that 121 out of $909(13.3 \%)$ of the cancers in this unselected population were HER2 + and that 105 out of $776(13.5 \%)$ patients had a HER2 + cancer (Table 2). HER2 positivity was associated with higher tumour grade, node positivity, higher NPI and the presence of LVI (Table 2 and Supplementary Table 2). Furthermore, HER2 status was associated with disease stage with $10.1 \%$ of stage I, $13.9 \%$ of stage II and $22.0 \%$ of stage III disease being HER $2+(P=0.006$, $X^{2}=10.27$, df 2 , data not shown). Although there was a negative association between HER2 status and ER and PR expression, because most of the cancers were $\mathrm{ER}+(81.1 \%)$, a majority $(57.0 \%)$ of HER $2+$ cancers were also ER + (Table 3$)$. 
Table 2 Clinical and pathological associations of patients by HER2 status

\begin{tabular}{|c|c|c|c|c|}
\hline & $\begin{array}{c}\text { HER2 - } \\
N(\%)\end{array}$ & $\begin{array}{c}\text { HER2+ } \\
\text { N (\%) }\end{array}$ & $\begin{array}{l}\text { Total } \\
\text { N (\%) }\end{array}$ & $P^{\mathbf{a}}$ \\
\hline $\begin{array}{l}\text { Screening } \\
\text { Symptomatic } \\
\text { Total }\end{array}$ & $\begin{array}{l}125(18.6) \\
546(81.4) \\
671(100.0)\end{array}$ & $\begin{array}{c}14(13.3) \\
91(86.7) \\
105(100.0)\end{array}$ & $\begin{array}{l}139(17.9) \\
637(82.1) \\
776(100.0)\end{array}$ & 0.22 \\
\hline $\begin{array}{l}\text { Grade } 1 \\
\text { Grade } 2 \\
\text { Grade } 3 \\
\text { Total }\end{array}$ & $\begin{array}{l}143(21.4) \\
298(44.5) \\
228(34.1) \\
669(100.0)\end{array}$ & $\begin{aligned} 1 & (1.0) \\
21 & (20.0) \\
83 & (79.0) \\
105 & (100.0)\end{aligned}$ & $\begin{array}{l}144(18.6) \\
319(41.2) \\
311(40.2) \\
774(100.0)^{b}\end{array}$ & $10^{-12}$ \\
\hline $\begin{array}{l}\text { Node negative } \\
\text { Node positive }(1-3) \\
\text { Node positive }(4+) \\
\text { Total }\end{array}$ & $\begin{aligned} & 411(61.7) \\
& 190(28.5) \\
& 65(9.8) \\
& 666(100.0)\end{aligned}$ & $\begin{array}{c}53(50.5) \\
31(29.5) \\
21(20.0) \\
105(100.0)\end{array}$ & $\begin{aligned} & 464(60.2) \\
& 221(28.7) \\
& 86(11.1) \\
& 771(100.0)^{c}\end{aligned}$ & 0.009 \\
\hline $\begin{array}{l}\text { GPG }(2.10-3.40)^{d} \\
\text { MPG }(3.41-5.40)^{d} \\
\text { PPG }(>5.40)^{d} \\
\text { Total }\end{array}$ & $\begin{array}{l}266(40.1) \\
265(39.9) \\
133(20.0) \\
664(100.0)\end{array}$ & $\begin{array}{c}12(11.4) \\
52(49.5) \\
41(39.1) \\
105(100.0)\end{array}$ & $\begin{array}{l}278(36.2) \\
317(41.2) \\
174(22.6) \\
769(100.0)^{\mathrm{b}, \mathrm{c}}\end{array}$ & $10^{-8}$ \\
\hline $\begin{array}{l}\text { LVI absent } \\
\text { LVI present } \\
\text { Total }\end{array}$ & $\begin{array}{l}510(76.0) \\
161(24.0) \\
671(100.0)\end{array}$ & $\begin{array}{c}64(61.0) \\
41(39.0) \\
105(100.0)\end{array}$ & $\begin{array}{l}574(74.0) \\
202(26.0) \\
776(100.0)\end{array}$ & 0.0018 \\
\hline $\begin{array}{l}\text { ER+ } \\
\text { ER- } \\
\text { Total }\end{array}$ & $\begin{array}{l}565(84.2) \\
106(15.8) \\
67 \mid(100.0)\end{array}$ & $\begin{array}{c}58(55.2) \\
47(44.8) \\
105(100.0)\end{array}$ & $\begin{array}{l}623(80.3) \\
153(19.7) \\
776(100.0)\end{array}$ & $10^{-10}$ \\
\hline $\begin{array}{l}\text { PR+ } \\
\text { PR- } \\
\text { Total }\end{array}$ & $\begin{array}{l}492(73.3) \\
179(26.7) \\
671(100.0)\end{array}$ & $\begin{array}{c}42(40.0) \\
63(60.0) \\
105(100.0)\end{array}$ & $\begin{array}{l}534(68.8) \\
242(31.2) \\
776(100.0)\end{array}$ & $10^{-10}$ \\
\hline
\end{tabular}

Abbreviations: $\mathrm{ER}=$ oestrogen receptor; $\mathrm{FISH}=$ fluorescent in situ hybridization $\mathrm{GPG}=$ good prognostic group; HER2 = human epidermal growth factor receptor 2; $\mathrm{LVI}=$ lymphovascular invasion; $\mathrm{MPG}=$ moderate prognostic group; $\overline{\mathrm{PPG}}=$ poor prognostic group; $P R=$ progesterone receptor. HER2 characteristics of the 776 surgically treated patients. ${ }^{a} \chi^{2}$ test with Yates' correction for $3 \times 2$ tables, two-sided Fisher's exact test for $2 \times 2$ tables. ' ${ }^{\text {Two }}$ cancers showed a $\mathrm{PCR}$ to neo-adjuvant chemotherapy. 'Five cancers had no axillary nodes as a result of previous axillary surgery. ${ }^{\mathrm{d}}$ Nottingham Prognostic Index.

Table 3 Association of HER2 status with hormone receptor expression

\begin{tabular}{lllll}
\hline & HER2- & HER2+ & Total (\%) & \\
& N (\%) & N (\%) & N (\%) & $\boldsymbol{P}^{\mathbf{a}}$ \\
\hline ER+ & $668(84.8)$ & $69(57.0)$ & $737(81.1)$ & \\
ER- & $120(15.2)$ & $52(43.0)$ & $172(18.9)$ & \\
Total & $788(100.0)$ & $121(100.0)$ & $909(100.0)^{\mathrm{b}}$ & $<10^{-8}$ \\
PR+ & $582(73.9)$ & $50(41.3)$ & $632(69.5)$ & \\
PR- & $206(26.1)$ & $71(58.7)$ & $277(30.5)$ & \\
Total & $788(100.0)$ & $121(100.0)$ & $909(100.0)^{\mathrm{b}}$ & $<10^{-8}$ \\
\hline
\end{tabular}

Abbreviations: ER = oestrogen receptor; HER2 = human epidermal growth factor receptor 2; PR = progesterone receptor. HER2 charäteristics of 910 biopsied cancers (core biopsies and surgical resections). ${ }^{a}$ Two-sided Fisher's exact test. ${ }^{b}$ One cancer had insufficient tissue for HER2 fluorescent in situ hybridization analysis.

\section{Survival}

Follow-up data for overall (breast cancer specific) and disease (relapse) free survival were obtained for all 776 patients $(100 \%)$ who underwent surgery (Table 4). HER2 positive status was associated with worse OS (log-rank test $X^{2}=8.027$, df 1 , $P=0.0046$ ) but HER2 status was not associated with prognosis by subgroup analysis for age at diagnosis, tumour grade or NPI group (data not shown). HER2 status was significantly associated with worse survival in LN + patients (log-rank test $X^{2}=6.571, \mathrm{df}$ $1, P=0.0104$; Figure 2A) but not in the LN - group (log-rank test $X^{2}=0.012$, df $1, P=0.912$; Figure $2 B$ ). In patients with $E R+$
Table 4 Outcome at 5 years

\begin{tabular}{|c|c|c|c|c|c|}
\hline & $\begin{array}{l}\text { 5-Year } \\
\text { DFS (\%) }\end{array}$ & $\begin{array}{l}\text { 5-Year } \\
\text { OS (\%) }\end{array}$ & $\chi^{2}$ & $P$ & $\begin{array}{c}\text { Hazard } \\
\text { ratio }\end{array}$ \\
\hline \multicolumn{6}{|l|}{ All cases } \\
\hline $\begin{array}{l}\text { HER2- } \\
\text { HER2+ }\end{array}$ & $\begin{array}{l}85.5 \\
73.0\end{array}$ & $\begin{array}{l}88.2 \\
78.8\end{array}$ & 8.027 & 0.0046 & $1.88 \mid$ \\
\hline \multicolumn{6}{|c|}{ Lymph node negative } \\
\hline $\begin{array}{l}\text { HER2- } \\
\text { HER2+ }\end{array}$ & $\begin{array}{l}91.6 \\
87.6\end{array}$ & $\begin{array}{l}93.8 \\
95.8\end{array}$ & 0.012 & 0.912 & $1.06 \mid$ \\
\hline \multicolumn{6}{|c|}{ Lymph node positive } \\
\hline $\begin{array}{l}\text { HER2- } \\
\text { HER2+ }\end{array}$ & $\begin{array}{l}75.9 \\
58.7\end{array}$ & $\begin{array}{l}79.7 \\
62.3\end{array}$ & 6.571 & 0.010 & 1.903 \\
\hline \multicolumn{6}{|l|}{$E R-$} \\
\hline $\begin{array}{l}\text { HER2- } \\
\text { HER2+ }\end{array}$ & $\begin{array}{l}58.5 \\
67.0\end{array}$ & $\begin{array}{l}62.3 \\
68.9\end{array}$ & 1.379 & 0.240 & 0.698 \\
\hline \multicolumn{6}{|l|}{$E R+$} \\
\hline $\begin{array}{l}\text { HER2 - } \\
\text { HER2+ }\end{array}$ & $\begin{array}{l}90.4 \\
77.8\end{array}$ & $\begin{array}{l}93.0 \\
86.9\end{array}$ & 7.465 & 0.006 & 2.434 \\
\hline
\end{tabular}

Abbreviations: $E R=$ oestrogen receptor; DFS = disease-free survival; HER2 = human epidermal growth factor receptor 2; OS = overall survival; $\mathrm{PR}=$ progesterone receptor. DFS and OS at 5 years were reported for 776 patients undergoing primary surgical therapy for breast cancer. Hazard ratio, $\chi^{2}$ and $P$-value for risk of death. Data derived from Kaplan-Meier analysis.

cancer, HER2 status was associated with a worse prognosis (logrank test $X^{2}=7.465$, df $1, P=0.0063$; Figure $2 \mathrm{C}$ ), whereas for the ER - group, HER2 positivity was not associated with a worse prognosis (log-rank test $X^{2}=1.379$, df $1, P=0.240$; Figure 2D).

Multivariate analysis using Cox's regression showed that HER2 status was not an independent prognostic variable in this population-based study when assessed along with the known prognostic predictors of tumour grade, size, LN status and ER (Table 5).

\section{DISCUSSION}

The patients and cancers in this study represent, uniquely, an unselected population of every patient who presented to a single geographically distinct cancer centre over a 3-year period. There was no selection bias on the basis of tumour size, grade, nodal status or disease stage and specimen processing, pathology review, IHC and FISH were tightly controlled.

The pathological parameters of the cancers in this study (tumour grade, tumour size and node status) were comparable with those in other studies (Elston, 1984; Elston and Ellis, 1991) and were associated with clinical outcome in the way that would be anticipated from previous published work (Galea et al, 1992). This indicates that the pathological assessment for the cohort presented is consistent with reported series (Elston, 1984; Elston and Ellis, 1991; Galea et al, 1992) and confirms the representative nature of the population studied.

Although there remains ongoing debate about the relative merits of IHC and FISH testing for routine clinical practice (Sauter et al, 2009) and whether further refinement of HER2 testing such as phospho HER2 analyses (Frogne et al, 2009) will add additional value remains to be seen, this series was based on current guidelines for HER2 testing (Ellis et al, 2000; Walker et al, 2008). The proportion of breast cancers in this series that were HER2 + was $13.3 \%$ overall with $13.5 \%$ of the patients undergoing surgery having a HER $2+$ cancer. These data are in keeping with national (UK) HER2 audit figures (Walker et al, 2008) but lower than most previously published series (Slamon et al, 1989; Seshadri et al, 
A

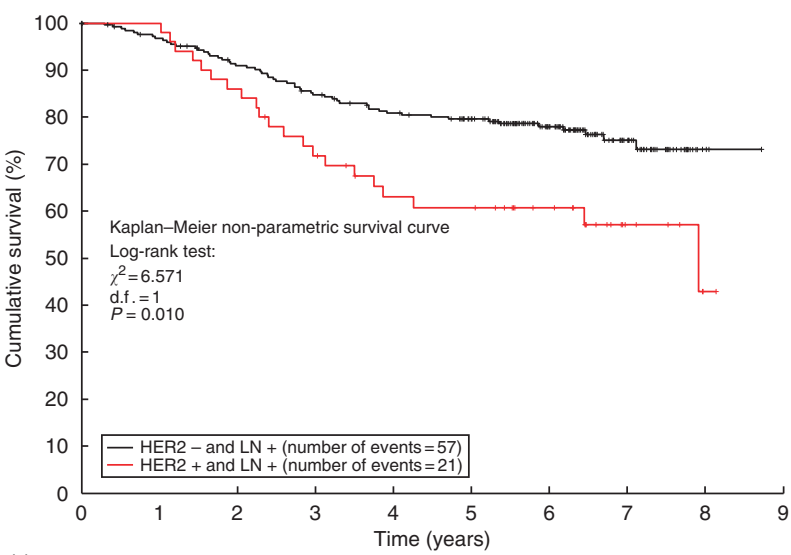

Number at risk


$\mathrm{HER} 2+$ and LN + 52

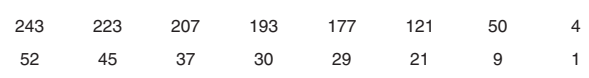

B

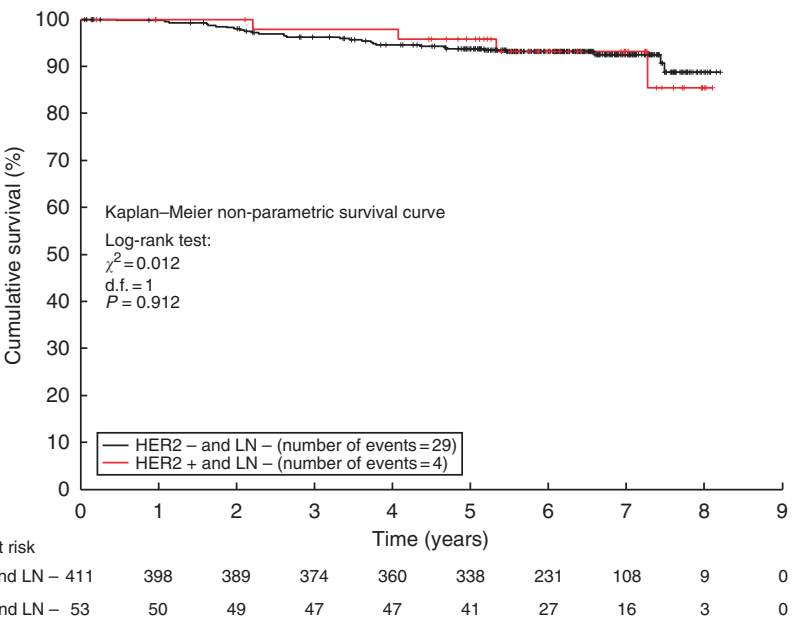

C



ڤ 50 Log-rank test:

$\stackrel{0}{\infty} 50-\begin{aligned} & \text { Log-rank te } \\ & \chi^{2}=7.465\end{aligned}$

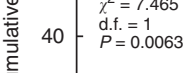

仓ु 30

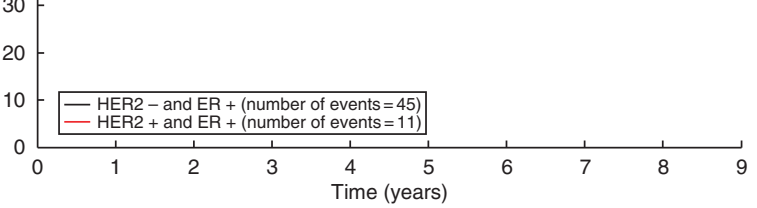

Number at risk

$\begin{array}{llllllllll}\text { HER2 - and ER + } 565 & 549 & 533 & 515 & 494 & 459 & 314 & 139 & 12 & 0\end{array}$

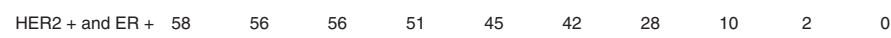

D

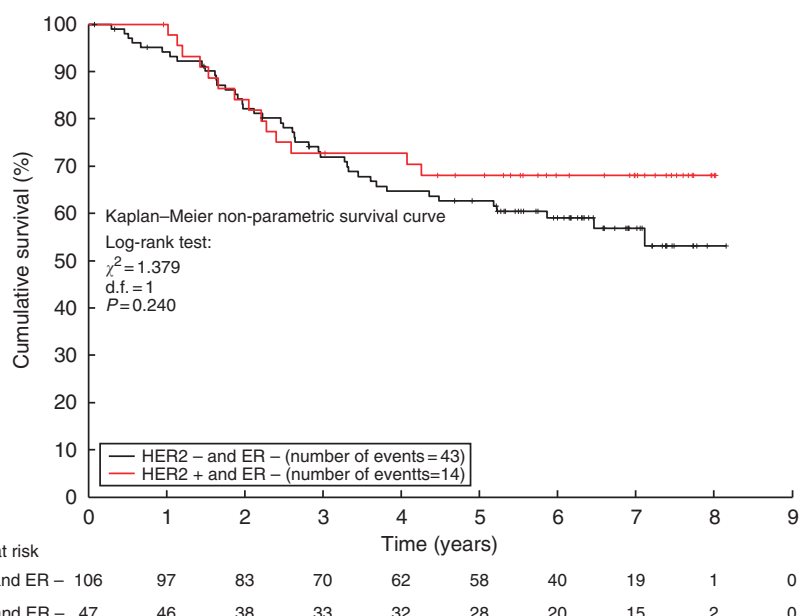

Figure 2 Kaplan-Meier plots of overall survival for HER2 status, (A) lymph node positive, (B) lymph node negative. (C) ER +, (D) ER-. HER2, human epidermal growth factor receptor 2; ER, oestrogen receptor.

Table 5 Cox's regression analysis (survival)

\begin{tabular}{lccc}
\hline \multicolumn{4}{c}{ Breast cancer death } \\
\hline Predictor & $\boldsymbol{\beta}$ & $\boldsymbol{P}$ & $\mathbf{R R ~ ( 9 5 \% ~ C l )}$ \\
\hline ER & -1.25 & $<0.001$ & $0.28(0.19-0.44)$ \\
LN status & 0.95 & $<0.001$ & $2.59(1.68-3.99)$ \\
Tumour size & 0.82 & $<0.001$ & $2.27(1.66-3.09)$ \\
Tumour grade 3 & 0.71 & 0.006 & $2.03(1.23-3.35)$ \\
HER2 status & $<0.01$ & 0.999 & $1.00(0.63-1.59)$ \\
\hline
\end{tabular}

Abbreviations: $\mathrm{Cl}=$ confidence intervals; $\mathrm{ER}=$ oestrogen receptor; $\mathrm{LN}=$ lymph node; $\mathrm{RR}=$ relative risk. Variables were analysed by Cox's proportional hazards regression model. Total number of cases 768 with 110 events. G-statistic $\chi^{2}=153.57, \mathrm{df}=5, P<0.000$ I. ER status, positive vs negative; $L N$ status, positive vs negative; tumour size, TI vs T2 vs T3; tumour grade 3 , grade 3 vs grades I and 2; HER2 status, positive vs negative.

1993; Press et al, 1997; Koeppen et al, 2001; Ellis et al, 2005; Crowe et al, 2006; Park et al, 2006), in which case selection for larger tumours to allow tumour sampling may have been used. This study includes $18 \%$ of cancers originating from a screening population, in which the preponderance of small, node-negative cancers may have a lower frequency of HER2 positivity (Chia et al, 2008; Frogne et al, 2009; Tovey et al, 2009). It is proposed that $13.3 \%$ is an accurate assessment of the prevalence of HER2 + breast cancer in a Western population with a high incidence of breast cancer.

The data show a clear and strong association between HER2 positivity and other poor prognostic features (Table 2), in keeping with previous studies (Seshadri et al, 1993), and the same associations between HER2 and tumour grade, nodal metastasis, lymphovascular invasion, ER and PR expression whether analysis was conducted by individual tumour or by patient. HER2 positivity was not, however, an independent prognostic factor on Cox's regression analysis. We found no association between HER2 status and age at presentation. Data from the selected populations suggest that HER2 positivity is seen more commonly in younger women (Gonzalez-Angulo et al, 2009), whereas others do not find this association (Chia et al, 2008; Tovey et al, 2009). This population-based study should give the most accurate assessment of the relationships between age and HER2 status and has failed to confirm any linkage.

As expected, HER2 + patients had significantly worse OS and DFS than HER2 - women (Slamon et al, 1987; Press et al, 1993). However, planned subset analysis showed that this was largely confined to the node-positive and ER + subgroups. The significance of HER2 status in node-negative cancers remains controversial, confounded by small series, differing methodologies, case selection bias and relatively short follow-up periods (Press et al, 1993; Seshadri et al, 1993; Ravdin and Chamness, 1995; Mirza et al, 2002) or series pre-selected for good prognostic 
features (Chia et al, 2008; Curigliano et al, 2009; Gonzalez-Angulo et al, 2009; Tovey et al, 2009); issues abrogated in the 776 surgical patients with a median follow-up of 6.02 years examined in this study. These findings indicate that the survival deficit for HER2 + cases is largely confined to node-positive cancers. However, trastuzumab is effective in the node-negative subgroup (Piccart-Gebhart et al, 2005), raising the intriguing possibility that the prognosis of such HER $2+$ patients may be therapeutically improved to exceed that of HER2 - patients at least in the nodenegative group.

Chemotherapy was given to $26.2 \%$ of the patients in this study. However, a significant difference in chemotherapy treatment with regard to HER 2 status was seen with $45.7 \%$ of HER $2+$ and $23.2 \%$ HER 2 - patients receiving chemotherapy $(P<0.0001)$. This significant difference was also present in the node-negative group with $25.0 \%$ of HER $2+$ and $7.5 \%$ of HER 2 - patients being given adjuvant chemotherapy $(P<0.001)$. At the time of treatment planning for the patients in this study, HER2 status was not being used as a factor in the process as this study predates the publication of the adjuvant trastuzumab clinical trials (PiccartGebhart et al, 2005; Romond et al, 2005; Smith et al, 2007; Perez and Baweja, 2008). Therefore, the increased use of chemotherapy in the HER $2+$ patients in this study reflects the association of HER2 positivity with other markers of tumour aggressiveness such as higher grade, higher stage and ER negativity (Tables 2 and 3 ). Thus, despite being more likely to have received adjuvant chemotherapy, the HER $2+$ patients had a worse survival. It is possible that the increased use of chemotherapy in the HER2 +, node-negative group could be responsible for improving their survival to be closer to the HER2-, node-negative group (Figure 2B). However, as only 43 of 454 node-negative patients $(9.5 \%)$ overall received adjuvant chemotherapy, this study is underpowered to confirm this point.

While this population-based cohort study confirms that HER2 + cancers have a worse DFS and OS, the proportion of HER2 + breast cancers (13.3\%) in this Caucasian, Western population is at the lower end of the published range (Slamon et al, 1989; Seshadri et al, 1993; Press et al, 1997; Koeppen et al, 2001; Ellis et al, 2005; Crowe et al, 2006; Park et al, 2006; Chia et al, 2008; Frogne et al, 2009; Tovey et al, 2009). However, this cohort analysis also highlights that women with ER,+ HER $2+$ cancers (69 out of $909(7.6 \%)$ of all cancers in 58 out of $776(7.5 \%)$ of all patients) have a significantly worse prognosis than those with $\mathrm{ER}+$, HER2 - disease. This finding is similar to other studies in which HER2 status was associated with DFS in ER + but not ER disease even in small, node-negative series (Curigliano et al, 2009), but different from some others in which the converse was observed (Chia et al, 2008; Gonzalez-Angulo et al, 2009). However, these studies were largely confined to specific subgroups of small, nodenegative cancers and looked at relapse-free survival. The strength of our study lies in the fact that it is population based, has full follow-up data on all of the patients and looks at OS as well as DFS.
Women with ER +, HER2 + cancers form a subgroup of patients for whom therapy targeting HER 2 could be particularly advantageous. As $46.6 \%$ of these patients (27 out of 58 ), were node negative and standard prognostic indicators such as NPI and Adjuvant! Online do not currently include HER2 status, the prognosis of these ER + /HER2 + patients may be overestimated. In all, $57 \%$ of the HER $2+$ patients in this series were also ER + . Although HER2 status did not influence survival in node-negative patients in this population-based study, subgroup analysis of the HERA study has shown that trastuzumab therapy improves DFS in node-negative, HER2 + disease (Piccart-Gebhart et al, 2005; Smith et al, 2007). There were only $27 \mathrm{ER}+, \mathrm{HER} 2+, \mathrm{LN}-$ patients in this series (27 out of $771,3.5 \%$ ), so it would not be justified to carry out survival analysis on such a small number of patients. It is noteworthy that the survival difference between ER,+ HER2 + and ER,+ HER 2 - patients only emerged after 3-4 years (Figure 2) so only longer follow-up of the large adjuvant trials and this series can be expected to elucidate whether node-negative patients should receive trastuzumab. It is possible that HER2 + , ER + , LN - patients may get further benefit from trastuzumab, which might improve DFS and OS to above that of HER2-, ER +, $\mathrm{LN}$ - disease.

Since the population of women reported in this study was diagnosed (2000-2003), adjuvant therapies directed against HER2 have become part of routine clinical practice. Therapy directed against HER2 (trastuzumab) can improve outcome in HER2 + breast cancers as adjuvant therapy along with chemotherapy (Piccart-Gebhart et al, 2005; Romond et al, 2005; Smith et al, 2007; Perez and Baweja, 2008), although the duration of follow-up in most studies is relatively short. Subgroup analysis of cases in the HERA study showed that trastuzumab is equally effective in both ER + and ER - cases (Piccart-Gebhart et al, 2005; Smith et al, 2007). However, guidelines in some countries (SIGN, 2005; Harnett et al, 2009) stipulate that trastuzumab can only be administered in the adjuvant setting (outwith clinical trials) to patients who also receive adjuvant chemotherapy. In our community-based series, a majority of HER2 + patients were ER $+(57 \%)$ and as their prognosis could be overestimated on conventional criteria, some risk being undertreated. They comprised $7.5 \%$ of all patients with operable tumours (Table 2) and nearly half (3.5\%) were node negative. The numbers are thus small but their management needs to be carefully evaluated to ensure that they are not undertreated.

\section{ACKNOWLEDGEMENTS}

We thank Professor Judith Bliss, Clinical Trials and Statistics Unit, The Institute of Cancer Research, Sutton, for her advice and encouragement in this study.

Supplementary Information accompanies the paper on British Journal of Cancer website (http://www.nature.com/bjc)

\section{REFERENCES}

National Health Service Breast Screening Programme (NHSBSP) Guidelines (1995) Pathology reporting in breast cancer screening. Publication No. 3

Buzdar AU, Ibrahim NK, Francis D, Booser DJ, Thomas ES, Theriault RL, Pusztai L, Green MC, Arun BK, Giordano SH, Cristofanilli M, Frye DK, Smith TL, Hunt KK, Singletary SE, Sahin AA, Ewer MS, Buchholz TA, Berry D, Hortobagyi GN (2005) Significantly higher pathologic complete remission rate after neoadjuvant therapy with trastuzumab, paclitaxel, and epirubicin chemotherapy: results of a randomized trial in human epidermal growth factor receptor 2-positive operable breast cancer. J Clin Oncol 23: 3676-3685
Chia S, Norris B, Speers C, Cheang M, Gilks B, Gown AM, Huntsman D, Olivotto IA, Nielsen TO, Gelmon K (2008) Human epidermal growth factor receptor 2 overexpression as a prognostic factor in a large tissue microarray series of node-negative breast cancers. J Clin Oncol 26: 5697-5704

Crowe JP, Patrick RJ, Rybicki LA, Escobar PF, Weng D, Thomas Budd G, Tubbs RR, Procop GW, Hicks DG (2006) A data model to predict HER2 status in breast cancer based on the clinical and pathologic profiles of a large patient population at a single institution. Breast 15: 728-735

Curigliano G, Viale G, Bagnardi V, Fumagalli L, Locatelli M, Rotmensz N, Ghisini R, Colleoni M, Munzone E, Veronesi P, Zurrida S, Nole F, Goldhirsch A (2009) Clinical relevance of HER2 overexpression/ 
amplification in patients with small tumor size and node-negative breast cancer. J Clin Oncol 27: 5693-5699

Detre S, Saclani Jotti G, Dowsett M (1995) A 'quickscore' method for immunohistochemical semiquantitation: validation for oestrogen receptor in breast carcinomas. J Clin Pathol 48: 876-878

Ellis CM, Dyson MJ, Stephenson TJ, Maltby EL (2005) HER2 amplification status in breast cancer: a comparison between immunohistochemical staining and fluorescence in situ hybridisation using manual and automated quantitative image analysis scoring techniques. J Clin Pathol 58: $710-714$

Ellis IO, Dowsett M, Bartlett J, Walker R, Cooke T, Gullick W, Gusterson B, Mallon E, Lee PB (2000) Recommendations for HER2 testing in the UK. J Clin Pathol 53: 890-892

Elston CW (1984) The assessment of histological differentiation in breast cancer. Aust N Z J Surg 54: $11-15$

Elston CW, Ellis IO (1991) Pathological prognostic factors in breast cancer. I. The value of histological grade in breast cancer: experience from a large study with long-term follow-up. Histopathology 19: $403-410$

Frogne T, Laenkholm AV, Lyng MB, Henriksen KL, Lykkesfeldt AE (2009) Determination of HER2 phosphorylation at tyrosine 1221/1222 improves prediction of poor survival for breast cancer patients with hormone receptor-positive tumors. Breast Cancer Res 11: R11

Galea MH, Blamey RW, Elston CE, Ellis IO (1992) The Nottingham Prognostic Index in primary breast cancer. Breast Cancer Res Treat 22: 207-219

Gonzalez-Angulo AM, Litton JK, Broglio KR, Meric-Bernstam F, Rakkhit R, Cardoso F, Peintinger F, Hanrahan EO, Sahin A, Guray M, Larsimont D, Feoli F, Stranzl H, Buchholz TA, Valero V, Theriault R, Piccart-Gebhart M, Ravdin PM, Berry DA, Hortobagyi GN (2009) High risk of recurrence for patients with breast cancer who have human epidermal growth factor receptor 2-positive, node-negative tumors $1 \mathrm{~cm}$ or smaller. J Clin Oncol 27: $5700-5706$

Harnett A, Smallwood J, Titshall V, Champion A (2009) Diagnosis and treatment of early breast cancer, including locally advanced disease summary of NICE guidance. BMJ 338: b438

Haybittle JL, Blamey RW, Elston CW, Johnson J, Doyle PJ, Campbell FC, Nicholson RI, Griffiths K (1982) A prognostic index in primary breast cancer. Br J Cancer 45: 361-366

King CR, Kraus MH, Aaronson SA (1985) Amplification of a novel v-erbBrelated gene in a human mammary carcinoma. Science 229: 974-976

Koeppen HK, Wright BD, Burt AD, Quirke P, McNicol AM, Dybdal NO, Sliwkowski MX, Hillan KJ (2001) Overexpression of HER2/neu in solid tumours: an immunohistochemical survey. Histopathology 38: 96-104

Menard S, Balsari A, Tagliabue E, Camerini T, Casalini P, Bufalino R, Castiglioni F, Carcangiu ML, Gloghini A, Scalone S, Querzoli P, Lunardi M, Molino A, Mandara M, Mottolese M, Marandino F, Venturini M, Bighin C, Cancello G, Montagna E, Perrone F, De Matteis A, Sapino A, Donadio M, Battelli N, Santinelli A, Pavesi L, Lanza A, Zito FA, Labriola A, Aiello RA, Caruso M, Zanconati F, Mustacchi G, Barbareschi M, Frisinghelli M, Russo R, Carrillo G (2008) Biology, prognosis and response to therapy of breast carcinomas according to HER2 score. Ann Oncol 19: 1706-1712

Mirza AN, Mirza NQ, Vlastos G, Singletary SE (2002) Prognostic factors in node-negative breast cancer: a review of studies with sample size more than 200 and follow-up more than 5 years. Ann Surg 235: 10-26

Moasser MM (2007) The oncogene HER2: its signaling and transforming functions and its role in human cancer pathogenesis. Oncogene 26: 6469-6487

Paik S, Kim C, Wolmark N (2008) HER2 status and benefit from adjuvant trastuzumab in breast cancer. $N$ Engl J Med 358: 1409-1411

Park K, Han S, Kim HJ, Kim J, Shin E (2006) HER2 status in pure ductal carcinoma in situ and in the intraductal and invasive components of invasive ductal carcinoma determined by fluorescence in situ hybridization and immunohistochemistry. Histopathology 48: 702-707

Perez EA, Baweja M (2008) HER2-positive breast cancer: current treatment strategies. Cancer Invest 26: 545-552

Piccart-Gebhart MJ, Procter M, Leyland-Jones B, Goldhirsch A, Untch M, Smith I, Gianni L, Baselga J, Bell R, Jackisch C, Cameron D, Dowsett M, Barrios CH, Steger G, Huang CS, Andersson M, Inbar M, Lichinitser M, Lang I, Nitz U, Iwata H, Thomssen C, Lohrisch C, Suter TM, Ruschoff J, Suto T, Greatorex V, Ward C, Straehle C, McFadden E, Dolci MS, Gelber RD (2005) Trastuzumab after adjuvant chemotherapy in HER2-positive breast cancer. N Engl J Med 353: 1659-1672

Press MF, Bernstein L, Thomas PA, Meisner LF, Zhou JY, Ma Y, Hung G, Robinson RA, Harris C, El-Naggar A, Slamon DJ, Phillips RN, Ross JS,
Wolman SR, Flom KJ (1997) HER-2/neu gene amplification characterized by fluorescence in situ hybridization: poor prognosis in node-negative breast carcinomas. J Clin Oncol 15: 2894-2904

Press MF, Pike MC, Chazin VR, Hung G, Udove JA, Markowicz M, Danyluk J, Godolphin W, Sliwkowski M, Akita R, Paterson MC, Slamon DJ (1993) Her-2/neu expression in node-negative breast cancer: direct tissue quantitation by computerized image analysis and association of overexpression with increased risk of recurrent disease. Cancer Res 53: 4960-4970

Purdie CA, Jordan LB, McCullough JB, Edwards SL, Cunningham J, Grant A, Pratt N, Thompson AM (2010) HER 2 assessment on core biopsies using monoclonal antibody CB11 accurately predicts HER2 status in breast carcinoma. Histopathology 56: $702-707$

Ravdin PM, Chamness GC (1995) The c-erbB-2 proto-oncogene as a prognostic and predictive marker in breast cancer: a paradigm for the development of other macromolecular markers - a review. Gene 159: $19-27$

Romond EH, Perez EA, Bryant J, Suman VJ, Geyer Jr CE, Davidson NE, Tan-Chiu E, Martino S, Paik S, Kaufman PA, Swain SM, Pisansky TM, Fehrenbacher L, Kutteh LA, Vogel VG, Visscher DW, Yothers G, Jenkins RB, Brown AM, Dakhil SR, Mamounas EP, Lingle WL, Klein PM, Ingle JN, Wolmark N (2005) Trastuzumab plus adjuvant chemotherapy for operable HER2-positive breast cancer. N Engl J Med 353: 1673-1684

Sauter G, Lee J, Bartlett JM, Slamon DJ, Press MF (2009) Guidelines for human epidermal growth factor receptor 2 testing: biologic and methodologic considerations. J Clin Oncol 27: 1323-1333

Schechter AL, Hung MC, Vaidyanathan L, Weinberg RA, Yang-Feng TL, Francke U, Ullrich A, Coussens L (1985) The neu gene: an erbBhomologous gene distinct from and unlinked to the gene encoding the EGF receptor. Science 229: $976-978$

Schechter AL, Stern DF, Vaidyanathan L, Decker SJ, Drebin JA, Greene MI, Weinberg RA (1984) The neu oncogene: an erb-B-related gene encoding a 185,000-Mr tumour antigen. Nature 312: 513-516

Seshadri R, Firgaira FA, Horsfall DJ, McCaul K, Setlur V, Kitchen P (1993) Clinical significance of HER-2/neu oncogene amplification in primary breast cancer. The South Australian Breast Cancer Study Group. J Clin Oncol 11: 1936-1942

Shih C, Padhy LC, Murray M, Weinberg RA (1981) Transforming genes of carcinomas and neuroblastomas introduced into mouse fibroblasts. Nature 290: $261-264$

SIGN (2005) Scottish Intercollegiate Guidelines Network(SIGN). Management of breast cancer in women. A national clinical guideline. $84 \mathrm{http}: / /$ www.sign.ac.uk/guidelines/fulltext/84/index.html

Slamon DJ, Clark GM, Wong SG, Levin WJ, Ullrich A, McGuire WL (1987) Human breast cancer: correlation of relapse and survival with amplification of the HER-2/neu oncogene. Science 235: 177-182

Slamon DJ, Godolphin W, Jones LA, Holt JA, Wong SG, Keith DE, Levin WJ, Stuart SG, Udove J, Ullrich A, Press MF (1989) Studies of the HER-2/neu proto-oncogene in human breast and ovarian cancer. Science 244: $707-712$

Slamon DJ, Leyland-Jones B, Shak S, Fuchs H, Paton V, Bajamonde A, Fleming T, Eiermann W, Wolter J, Pegram M, Baselga J, Norton L (2001) Use of chemotherapy plus a monoclonal antibody against HER2 for metastatic breast cancer that overexpresses HER2. $N$ Engl J Med 344: $783-792$

Smith I, Procter M, Gelber RD, Guillaume S, Feyereislova A, Dowsett M, Goldhirsch A, Untch M, Mariani G, Baselga J, Kaufmann M, Cameron D, Bell R, Bergh J, Coleman R, Wardley A, Harbeck N, Lopez RI, Mallmann P, Gelmon K, Wilcken N, Wist E, Sanchez Rovira P, Piccart-Gebhart MJ (2007) 2-year follow-up of trastuzumab after adjuvant chemotherapy in HER2-positive breast cancer: a randomised controlled trial. Lancet 369: $29-36$

Tovey SM, Brown S, Doughty JC, Mallon EA, Cooke TG, Edwards J (2009) Poor survival outcomes in HER2-positive breast cancer patients with low-grade, node-negative tumours. Br J Cancer 100: 680 -683

Walker RA, Bartlett JM, Dowsett M, Ellis IO, Hanby AM, Jasani B, Miller K, Pinder SE (2008) HER2 testing in the UK: further update to recommendations. J Clin Pathol 61: 818-824

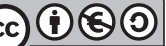

This work is licensed under the Creative Commons Attribution-NonCommercial-Share Alike 3.0 Unported License. To view a copy of this license, visit http://creativecommons. org/licenses/by-nc-sa/3.0/ 